
\title{
3 Research S Suare \\ Iron Overload and Outcomes in Very Low Birth Weight Infants
}

\section{Michael J Barrett}

$\mathrm{CHI}$ : Children's Health Ireland at Crumlin

\section{Roberta McCarthy}

National Maternity Hospital

Ailbhe McGrath ( $\nabla$ ailbhemcgrth@gmail.com )

Coombe Women and Infants University Hospital https://orcid.org/0000-0003-1653-9556

\section{Marie Slevin}

National Maternity Hospital

\section{Veronica Donoghue}

National Maternity Hospital

\section{Alan Macken}

South Tipperary General Hospital

\section{Bridget Freyne}

University of Liverpool IGH: University of Liverpool Institute of Infection and Global Health

\section{Ghia Kissoon-Harrison}

Sligo University Hospital

\section{Eman Isweisi}

Trinity College Dublin: The University of Dublin Trinity College

\section{John Quigley}

Mullingar General Hospital: Midland Regional Hospital Mullingar

\section{Eleanor J Molloy}

Coombe Women and Infants University Hospital

\section{Research Article}

Keywords: Iron, infant, Very Low Birth Weight, Ferritin, Iron overload

Posted Date: March 15th, 2021

DOl: https://doi.org/10.21203/rs.3.rs-287982/v1

License: (1) This work is licensed under a Creative Commons Attribution 4.0 International License. Read Full License 


\section{Abstract}

Iron is essential for growth and haematopoiesis but iron overload can have detrimental effects. The aim of this study is to correlate iron indices at 1 month of age in very low birth weight infants undergoing intensive care prior to additional iron supplementation and correlate results with clinical measures and 2 year corrected neurodevelopmental outcomes.

A prospective observational cohort study was undertaken of very low birth weight infants at a tertiary neonatal intensive care unit.

In 45 eligible infants, iron overload existed in 14 (31\%) who had significantly decreased: mean (SD) gestational age at birth [26(2) v 28(2) weeks], birth weight [814(231)g v1011(238)g], weight on assessment [1180(369) g v 1502(423)g], haemoglobin level at birth [13.8(3.1)g/dL $\vee 16.1(2.5) \mathrm{g} / \mathrm{dL}]$ and mean corpuscular volume at assessment [85(4) $\mathrm{fL} \vee 90(6) \mathrm{fL}]$ with increased number of red cell transfusions [4(2.5-5) $\vee 1(0-2)]$ and volume of transfusions [65 (38) $\mathrm{mL} \vee 27(23) \mathrm{mL}]$. Regression analysis determined the number of transfusions had the strongest correlation with iron status on testing. Neurodevelopmental outcomes at 2 years were not significantly different.

Conclusion: Very low birth weight infants at risk of iron overload ( $\geq 2$ red cell transfusions) may benefit from the measurement of iron indices prior to oral iron supplementation.

\section{What Is Known}

- Preterm infants often require blood transfusions and oral iron supplementation in the management of anaemia of prematurity.

- Excessive free iron has been associated with brain injury in models of hypoxic-ischemic brain injury and infection

\section{What Is New}

- Iron overload is a significant finding in preterm very low birth weight infants, especially in those receiving multiple red blood cell transfusions.

- Further iron supplementation may potentially be harmful in infants with iron overload.

\section{Introduction}

Iron essential for growth and haematopoiesis but excessive free iron has been associated with brain injury in models of hypoxic-ischemic brain injury and infection [1-4]. Preterm neonates require iron supplementation in the management of anaemia of prematurity and receive red cell transfusions contributing to iron load. Low circulating levels of transferrin and other iron-binding proteins in preterm infants allow increased circulation of non-protein-bound iron. Neonatal animal models have shown a predisposition to iron overload due to an inability to down-regulate their iron absorption [5]. 
There is no definitive test to measure iron overload in preterm infants, and elevated serum ferritin is a nonspecific indicator of severe hepatocyte injury and inflammation. Iron plays a vital role in cellular function in all organ systems and is essential for optimal development and function [3]. It is routine to supplement iron in preterm infants to prevent iron deficiency anaemia. The optimum dose, duration and point of intervention with iron supplementation in preterm and low birth weight infants has yet to be determined, though the recommended enteral iron intake for very low birth weight (VLBW) infants is 2$3 \mathrm{mg} / \mathrm{kg} /$ day [6]. Serum ferritin (SF) concentration, a measure of tissue iron stores, is currently considered the best surrogate biochemical measure of iron overload in the absence of active infection or elevated Creactive protein [7]. Excess exogenous iron may contribute to oxidative injury in preterm babies exacerbating conditions such as necrotising enterocolitis, retinopathy of prematurity, bronchopulmonary dysplasia and inducing neuronal injury $[3,4,8,9]$. We aimed to correlate iron indices with clinical measures and 2 years corrected neurodevelopmental outcomes in VLBW infants.

\section{Method}

Ethical committee approval was received from a tertiary referral, university-affiliated maternity hospital for this prospective study of infants birth weight $<1500 \mathrm{~g}$ admitted to the neonatal intensive care unit (NICU). Iron indices [ferritin, transferrin, transferrin saturation, total iron binding capacity (TIBC), iron], full blood count, biochemistry profile, liver profile (transaminases, albumin, bilirubin), C-reactive peptide (CRP) were measured prior to the initiation of routine oral iron supplements. Infants were excluded if infection was suspected or confirmed acute illness, recipients of a red cell concentrate transfusion (RCC Tx) in the previous 48 hours, chromosomal disorders, discharged or died prior to achievement of full enteral feeds.

Serum ferritin (SF) is a clinically available proxy measure for iron status in the absence of confounders. The upper limit of normal of serum ferritin $(300 \mathrm{mg} / \mathrm{L})$ was derived from Obladen et al, where on days 24$26(n=128)$ the 90 th percentile was 300 and the 97 th percentile was $383 \mathrm{mg} / \mathrm{L}(383 \mathrm{ng} / \mathrm{mL})[9,10]$. Serum ferritin less than $12 \mathrm{ng} / \mathrm{L}$ was suggestive of iron deficiency in preterm infants [3]. Neurodevelopmental assessment was conducted by a developmental psychologist (MS) at 2 years of age corrected using the Bayley Scales of Infant and Toddler Development (Bayley-III). Serial cranial ultrasounds at 0-24h, 24-72h, day 7 , one month and day of discharge were performed by paediatric radiologist (VD) with an interest in neonatal brain injury. Magnetic resonance imaging (MRI) was conducted at 2 years corrected.

\section{Statistics}

Statistical analysis was performed using SPSS version 18. Analysis of Gaussian and non-Gaussian data used unpaired t-test and Mann-Whitney test, respectively. Paired data was analysed by paired t-test or Wilcoxon test. Categorical variables were reported as percentages and binomial measurements were compared using $\chi 2$ test. Quantification of the relationships was determined using Spearman and Pearson correlations. Stepwise logistic regression modelling was performed to identify variables associated with the iron status. In a stepwise fashion covariates that did not make a statistically significant contribution 
$(p>0.1)$ to the model were removed from the model. All tests were two sided and a $p<.05$ was considered statistically significant.

\section{Results}

During a study period of 9 months, 84 infants were potentially eligible for inclusion. The exclusions were as follows: discharged from the NICU prior to 1 month of age $(n=21)$; haemolysed sample $(n=6)$; infection, recent transfusion ( $<48 \mathrm{~h}$ ), necrotising enterocolitis (NEC) or acutely unwell $(n=8)$ and 4 patients died. Forty-five infants were included and divided into 2 groups with normal iron status (ferritin level 12-300 $\mathrm{ng} / \mathrm{mL}$ ) or iron overload (elevated ferritin level $>300 \mathrm{ng} / \mathrm{mL}$ ) (Table 1).

The mean (SD) gestational age and birth weight of the entire cohort was 27(2) weeks and 949 (251) grams respectively. There were 20 female and 25 male infants. Fourteen infants were iron overloaded (Table 1). Infants with iron overload had a significantly lower gestational age at birth, birth weight, weight on assessment, haemoglobin at birth, and mean corpuscular volume at assessment with significantly increased number of transfusions and volume of erythrocyte transfusions (Table 1). No significant relationship or correlation between maternal preeclampsia, number of days to establish full feeds, type of feed (breast milk with or without non-iron rich fortifier or formula milk), presence of intraventricular haemorrhage, incidence of high frequency oscillatory ventilation, usage of postnatal steroids, necrotising enterocolitis, presence of patent ductus surgery, liver transaminases, total bilirubin and C-reactive peptide was established between groups. The relationship between duration of intermittent positive pressure ventilation and retinopathy of prematurity was not significant between comparison groups.

Serial cranial ultrasound evaluation and neurodevelopmental outcomes (cognition, language and motor outcomes) at two years were not significantly different between the groups. Nine infants had 2-year follow-up MRIs and there was no predominance of abnormal MRI in either group. Three of the five MRIs revealed periventricular white matter abnormalities, individual cases separately revealed deep white matter abnormalities, cortical dysplasia and abnormal myelination.

Correlation analysis of the entire cohort revealed a significant negative association between ferritin levels and gestation, birth weight, haemoglobin at birth, and weight on testing. A significant positive association was identified between ferritin levels and the number of erythrocyte transfusions, total transfused blood volume, daily iron intake, the duration of invasive ventilation and mean corpuscular volume on testing. All patients $(n=8)$ who received 3 or more blood transfusions had iron overload. Four of nine patients (44\%) who received 2 transfusions were overloaded and 1 of $7(14 \%)$ who received 1 transfusion. Total iron intake including iron from feeds and RCC transfusions was significantly increased in those infants with iron overload. The factors identified to be associated with iron status with a $p<0.1$ (Table I) were included in the model building for linear regression analysis. Stepwise logistic regression determined that the relationship (B) between every erythrocyte transfusion received, the ferritin increased by $62 \mathrm{ng} / \mathrm{mL}(B=$ $62 \mathrm{ng} / \mathrm{ml}, 95 \% \mathrm{Cl} 28$ to $96, \mathrm{p}<0.001)$. Regression determined that the relationship (B) for every increasing 
gram of weight on testing the ferritin decreased by $0.169 \mathrm{ng} / \mathrm{mL}(\mathrm{B}=-0.169 \mathrm{ng} / \mathrm{ml}, 95 \% \mathrm{Cl}-0.317$ to -0.021 , $\mathrm{p}=0.027$ ). No infant had a ferritin less than $12 \mathrm{ng} / \mathrm{mL}$.

\section{Discussion}

Nutritional iron supplementation is routine in most neonatal units without a baseline clinical or laboratory assessment of iron status. The immaturity of the regulation of gastrointestinal iron absorption and potential for increased cerebral uptake and neuronal injury with excess amounts of iron supplementation in preterm infants is unknown $[3,5,9,11]$.

This study uniquely assessed iron status prior to additional oral iron supplementation and discovered 14 (31\%) infants with iron overload which is higher than previously reported at just $19 \%$ at 35 weeks corrected [12]. All 8 infants who received 3 or more RCC Tx met criteria for iron overload which is also higher than previously reported at just $50 \%$ at 35 weeks corrected [12], although the cohort in our study were of lower gestational age with no significant difference between the total iron from feeds and iron status. Stepwise linear logistic regression modelling established a significant relationship between number of erythrocyte transfusions and weight at assessment with ferritin level. There was no significant impact on neurodevelopmental outcomes at 2 years associated with iron overload, which supports the neurodevelopmental findings of Amin et al at 8 to 12 months, extending it to 2 year outcomes [13].

The strengths of our study are that its prospective nature, using a well-accepted biological test that is readily available in clinical practice. We performed the analysis upon a uniform population which was defined prior to testing and prior to intervention with additional enteral iron supplements. However, the study is limited by relatively small numbers.

Our findings suggest that iron status at 1 month is extremely variable among preterm VLBW infants and is predicted by the number of blood transfusions prior to additional oral iron supplementation. We suggest that infants at risk of iron overload (i.e. $\geq 2$ transfusions received) should have iron indices measured prior to starting iron supplementation. For infants with iron overload, iron supplementation may be potentially harmful and future studies are required to study this and to determine the optimal dose, timing and contraindications to iron supplementation for preterm infants.

\section{Declarations}

\section{ACKNOWLEDGEMENTS:}

We would like to acknowledge the support and assistance of the parents and staff in the Neonatal Intensive Care unit of the National Maternity Hospital. We would like to acknowledge Dr. Ranawaya for the contribution to data collection.

\section{Funding:}


None

\section{Competing interests:}

None declared

\section{Ethics approval:}

Ethical approval was obtained from the National Maternity Hospital Ethics Board, National Maternity Hospital, Holles Street, Dublin, Ireland. An approval number was not obtained as this was not practiced by the committee at the time.

\section{Consent to participate:}

Not applicable. All phlebotomy and follow-up was part of routine care in the neonatal unit.

\section{Consent for publication:}

Not applicable.

\section{Availability of data and material:}

All data collected was anonymised and stored in electronic format on locked hospital property and was destroyed thereafter as per hospital ethical guidelines.

\section{Code availability:}

Not applicable.

\section{Authors' contributions:}

MJB wrote the paper, and gave substantial contributions to the conception and design of the work, the acquisition, analysis and interpretation of data for the work. RMC co-designed and conceived the project and revised the manuscript. AMG revised and reviewed the manuscript for publication. MS conducted the neurodevelopmental assessments and revised the manuscript. VD performed and scored neuroimaging and revised the manuscript. AM co-designed the project and contributed to data collection and manuscript review and revision. BF gave substantial contributions to the conception and design of the work and the acquisition, analysis, and interpretation of data for the work. GH gave substantial contributions to the conception and design of the work, the acquisition, analysis and interpretation of data for the work. El gave substantial contributions to the conception and design of the work, the acquisition, analysis and interpretation of data for the work. JQ analysed blood samples and gave substantial contributions to the conception and design of the work, the acquisition, analysis and interpretation of data for the work. EJM designed, supervised the project and co-wrote the paper. All authors were involved in drafting the work or revising it critically for important intellectual content, final approval of the version to be published and agreement to be accountable for all aspects of the work in 
ensuring that questions related to the accuracy or integrity of any part of the work are appropriately investigated and resolved.

\section{References}

1. Georgieff MK. (2007) Nutrition and the developing brain: nutrient priorities and measurement. Am J Clin Nutr. 2007;85(2):614S-20S. Epub 2007/02/08.

2. Rao R, Georgieff MK. (2007) Iron in fetal and neonatal nutrition. Semin Fetal Neonatal Med. 2007;12(1):54-63. Epub 2006/12/13.

3. Rao R, Georgieff MK. (2009) Iron therapy for preterm infants. Clin Perinatol. 2009;36(1):27-42. Epub 2009/01/24.

4. Georgieff MK, Innis SM. (2005) Controversial nutrients that potentially affect preterm neurodevelopment: essential fatty acids and iron. Pediatric research. 2005;57(5 Pt 2):99R-103R. Epub 2005/04/09.

5. Leong WI, Bowlus CL, Tallkvist J, Lonnerdal B. (2003) Iron supplementation during infancy-effects on expression of iron transporters, iron absorption, and iron utilization in rat pups. Am J Clin Nutr. 2003;78(6):1203-11. Epub 2003/12/12.

6. Koletzko B, Poindexter B, Uauy R. (2014) Nutritional Care of Preterm Infants: Scientific Basis and Practical Guidelines. World Rev Nutr Diet. Basel Karger. 2014; 110: 121-139 (DOI: 10.1159/000358462)

7. Wang Y, Wu Y, Li T, Wang X, Zhu T. (2019) Iron Metabolism and Brain Development in Preamture Infants. Front. Physiol., 25 April 2019 |https://doi.org/10.3389/fphys.2019.00463

8. Mills RJ, Davies MW. (2012) Enteral iron supplementation in preterm and low birth weight infants. Cochrane Database Syst Rev. 2012;3:CD005095. Epub 2012/03/16.

9. Molloy EJ, El-Khuffash A, Bieda A, Jelinek MM, Baley J. (2019) Elevated iron indices in preterm infants: association with male gender. Am J Perinatol. 2009;26(1):7-11. Epub 2008/11/22.

10. Obladen M, Diepold K, Maier RF. (2000) Venous and arterial hematologic profiles of very low birth weight infants. European Multicenter rhEPO Study Group. Pediatrics. 2000;106(4):707-11. Epub 2000/10/04.

11. Kaur D, Peng J, Chinta SJ, Rajagopalan S, DiMonte DA, Cherny RA, Andersen JK. (2007) Increased murine neonatal iron intake results in Parkinson-like neurodegeneration with age. Neurobiol Aging. 2007;28(6):907-13. Epub 2006/06/13.

12. Amin SB, Scholer L, Srivastava M. (2012) Pre-discharge iron status and its determinants in premature infants. J Matern Fetal Neonatal Med. 2012; 25(11): 2265-2269 Epub 2012/06/29

13. Amin SB, Myers G, Wang H. (2012) Association between neonatal Iron Overload and Early Human Brain Development in Premature Infants. Early Hum Dev. 2012; 88(8): 583-587 Epub 2012/02/18

\section{Tables}


Table 1: Significant and non-significant associations between iron overloaded and normal infant groups

\begin{tabular}{|llll|}
\hline Parameters & $\begin{array}{l}\text { Normal iron status } \\
(\mathbf{n = 3 1})\end{array}$ & $\begin{array}{l}\text { Iron overload } \\
(\boldsymbol{n}=\mathbf{1 4})\end{array}$ & p value \\
\hline Serum Ferritin $(\mathrm{ng} / \mathrm{mL})$ & $152(69)$ & $565(189)$ & $<0.0001$ \\
\hline GA (weeks) at birth & $28(2)$ & $26(2)$ & 0.020 \\
\hline Birth weight (g) & $1011(238)$ & $814(231)$ & 0.013 \\
\hline RCC Transfusions & $1(0-2)$ & $4(2.5-5)$ & $<0.0001$ \\
\hline Total volume of RCC Transfusions $(\mathrm{mL})$ & $27(23)$ & $65(38)$ & 0.003 \\
\hline Iron intake feeds $(\mathrm{mg} / \mathrm{g} / \mathrm{day}){ }^{* *}$ & $1.3(0.5)$ & $1.7(1.1)$ & 0.066 \\
\hline Total Iron intake $\left(\mathrm{mg} / \mathrm{g} /\right.$ day) ${ }^{\circ}$ & $4.5(6)$ & $9.4(4.4)$ & 0.005 \\
\hline Day of life on assessment (day) & $33(6)$ & $36(10)$ & $\mathrm{n} / \mathrm{s}$ \\
\hline Weight on testing (g) & $1502(423)$ & $1180(369)$ & $<0.0001$ \\
\hline Hgb (g/dL) birth & $16.1(2.5)$ & $13.8(3.1)$ & 0.012 \\
\hline Hgb (g/dL) at assessment & $10.6(1.8)$ & $10.3(1.7)$ & $\mathrm{n} / \mathrm{s}$ \\
\hline MCV (fL) ${ }^{\circ}$ & $90(6)$ & $85(4)$ & 0.011 \\
\hline Duration of IPPV & $5(9)$ & $13(12)$ & 0.055 \\
\hline Retinopathy of Prematurity & 5 & 7 & 0.072 \\
\hline
\end{tabular}

Normally distributed variables are expressed at mean and standard deviation. Non-normal distributed variables are expressed as median and interquartile range. RCC=Erythrocyte transfusion, ${ }^{\circ}$ Iron from feeds and RCC transfusions, HgB: Haemoglobin, MCV: Mean corpuscular Volume, IPPV: Invasive Positive Pressure Ventilation ** Average Iron intake from feeds (mg iron per gram weight gain per day); ${ }^{\circ}$ Total Averaged Iron intake (mg iron per gram of weight gain per day) 